\title{
Exploration and Practice of CDIO-Based Innovation Talent Training Mode for Biological Engineering Major in Local Universities
}

\author{
Yanhong Wang ${ }^{*}$, Yongzhong Yu, Yuan Yuan, Zhe Liu, Liyang Li
}

College of Life Science and Technology, HeiLongJiang BaYi Agricultural University, Daqing 163319, China

DOI: $10.36347 /$ sjet.2020.v08i08.001

| Received: 26.07.2020 | Accepted: 03.08.2020 | Published: 05.08.2020

*Corresponding author: Yanhong Wang

Abstract

Review Article

CDIO is an OBE education mode that drives the whole educational system including curriculum plan, teachers, teaching methods and practice places with the expected graduate ability. In order to respond to the objectives of the 13th Five-Year Plan and meet the development needs of the future bioengineering industry, Heilongjiang Bayi Agricultural University launched the CDIO training concept and applied it to the training of bioengineering professionals. This study shows that the CDIO cultivation concept can improve the comprehensive cultivation level of bioengineering majors in local colleges and universities.

Keywords: CDIO, Biological Engineering Major, Teaching Reform, Mode.

Copyright @ 2020: This is an open-access article distributed under the terms of the Creative Commons Attribution license which permits unrestricted use, distribution, and reproduction in any medium for non-commercial use (NonCommercial, or CC-BY-NC) provided the original author and source are credited.

\section{INTRODUCTION}

As a comprehensive and applied discipline, bioengineering requires students not only to master solid professional theoretical knowledge, but also to undergo rigorous professional practical skills training, so as to meet the development needs of the future bioengineering industry. At present, the biological engineering industry talent is insufficient, therefore, Heilongjiang BaYi Agricultural University launched CDIO cultivating idea, the idea has the international advanced, practical operability and comprehensive systemic and general applicability, to cultivate the innovation ability of college students provides a new possible, to improve the level of higher engineering education in China is of great significance.

\section{CULTIVATION OF TALENTS}

\section{To cultivate talents in biological engineering}

Biological engineering as a strong comprehensive and applied discipline has long been concern, and to train creative talents with ability to create new products, it is "much starker choices-and graver consequences-in planning" important instructions, in response to "much starker choices-and graver consequences-in" strategic planning goals, biological engineering in colleges and universities are open to biological engineering professional talent training mode to explore innovative undertaking. Heilongjiang BaYi Agricultural University as local undergraduate colleges and universities, to cultivate qualified biological engineering professionals, with international engineering education reform and development trends of engineering education accreditation, with mature CDIO (Conceiving Designing - Implementing - Operation) training concept, namely the conception, design, implementation and running process as the carrier using modern teaching theory, the innovation teaching method, provides the new learning environment, to cultivate the students' engineering ability, the ability to not only contain personal academic knowledge, it also includes students' ability to learn throughout their lives, communicate in teams, and control large systems [1]. This process is internationally advanced, practicable, comprehensive and systematic, and generally adaptable. Therefore, the CDIO engineering education mode provides a new possibility for cultivating the innovation ability of college students. Through the reform of CDIO higher engineering education, the professional structure can be more comprehensive and the degree of course integration can be improved. This kind of integrated knowledge education can enhance the comprehensive ability of students and improve their international competitiveness.

\section{Overview of CDIO concept talent cultivation system construction in foreign universities}

Since October 2000, Edward F. Crawley et al., [2] of Massachusetts Institute of Technology, as the founders of CDIO mode, have done a lot of 
groundbreaking research on its theory and practice, and established CDIO International Cooperation Organization in 2004. In 2007, he published a monograph, which systematically elaborated and demonstrated the CDIO training mode. In 2011, Edward F. Crawley et al. published CDIO syllabus (2.0). Since its birth, CDIO mode has been popularized and applied in many countries. In 2001, CDIO mode was promoted in MIT and other famous universities; in 2002, Technical University of Denmark joined in the cooperation; in 2003, Canada and the United Kingdom joined in [3].

In 2005, the Swedish higher engineering education sector applied the CDIO standard to the National Education Assessment of Sweden [4], and the CDIO standard was constantly revised through the survey of stakeholders. Lcion Benedict Popp et al., compared and evaluated the CDIO syllabus with the Australian Engineer Qualification standards and the Curriculum plan of the University of Sydney, and finally formed a new set of rules framework.

\section{Reformed and practiced the biological engineering}

In essence, CDIO is an OBE education mode that drives the entire educational system (curriculum plan, teachers, teaching methods and practice places) with the expected graduates' abilities [5]. This training mode has the following characteristics: Condenses the engineering course content into one or several exploration projects, which form different levels due to the different degree of knowledge or difficulty involved; Define the expected learning outcomes of the project; Carefully design the learning situation, so that the students experience the inquisitive teaching each step of the training; Evaluate students' learning results and then give feedback.

Constructed the comprehensive practice teaching system of professional cognition practice, course experiment, course design, production practice and graduation design

We will strengthen the construction of "industry-Study-Research" practice base to improve the production practice effect. Relying on Daqing Huali Energy Biotechnology Co., Ltd. and Daqing Furuibang Pharmaceutical Co., LTD., we will establish the practice and training base involving biological engineering specialty to standardize, stabilize and prolong the operation of the existing practice base. The cooperative research and development teaching base agreement is signed with enterprises to meet the needs of students' experiment, practical training and internship, and the scientific and technological innovation and scientific research results are applied to practical teaching to realize the integration of "production, study and research". Reform implementation process, improve the quality of graduation design in view of the graduation thesis complete laboratory during stressful, and students employment problem such as time conflict, to reform the current implementation process, starting from a freshman, lets the student choice for laboratory, implement "tutorial system" [6], not only ensure the effective experiment time, and improve the quality of graduation thesis, cultivate the excellent team of graduation design or paper.

\section{Established a core curriculum group}

Based on CDIO teaching idea [7], we bioengineering first-line teachers after continuous efforts, the integration of multiple core courses each main class in the main point and clarify the teaching content of each course are relatively independent and the intrinsic relationship between various curriculum, and select the part of the course using "flip teaching", "blue ink cloud class" and other modern teaching means can make students in the four years of undergraduate course time grasp and discover problems, analyze and solve problems, teamwork and communication skills. According to the CDIO concept, we explored and established the core curriculum group of bioengineering major.

\section{Established extracurricular "innovation credit" system}

Planning a series of extra-curricular social practice projects, participating in teachers' scientific research or educational reform activities, off-campus enterprise training activities, social practice activities, professional certification examinations, various discipline competitions, academic papers, university students' scientific and technological innovation, entrepreneurship projects, etc., which can be counted as innovation credits. Extracurricular "innovative credit" activities enable students to be exposed to the "industryuniversity-research" environment, broaden their horizons, exercise their abilities, and promote the transformation of students' learning activities from "teacher-centered" to "student-centered" [8].

\section{Established student assessment system}

In most engineering institutions, the student assessment system is largely determined by mid-term or final exam results. In the CDIO mode, learning assessment not only focuses on theoretical knowledge of the subject, but also attaches importance to basic personal ability, interpersonal skills and ability to build products and systems. In order to cultivate innovative talents, we examine the comprehensive quality of students from many aspects. First of all, through the examination of theoretical knowledge of the course, namely the final or mid-term examination to check the students' knowledge; Secondly, students' practical engineering ability is evaluated comprehensively through simple CDIO project products or design and group products or design. Through the comprehensive evaluation of students' various CDIO abilities, the total scores of students are given at last. The figure- 1 is the model of CDIO. 


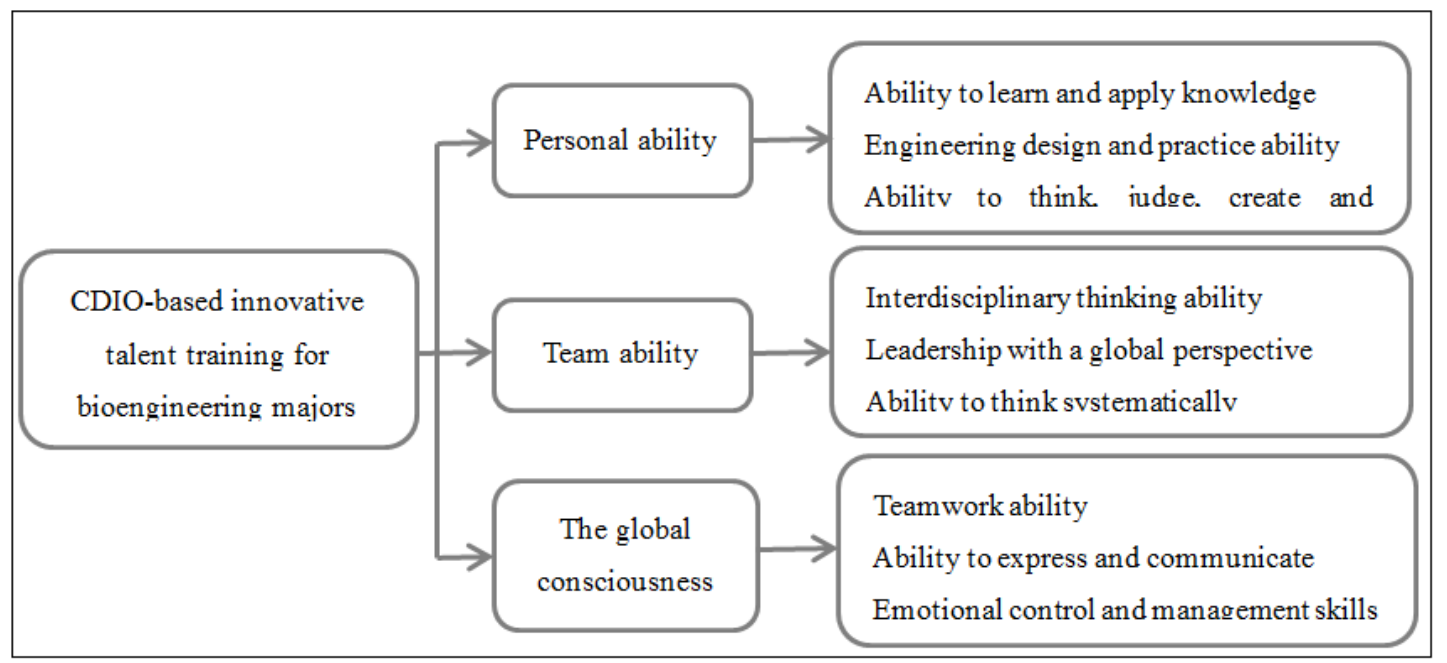

Fig-1: Model of CDIO

\section{CONCLUSION}

In this study, the CDIO concept is applied to the cultivation of talents in biological engineering majors. Combined with China's characteristic education system, the characteristics and advantages of this mode are given full play to carry out comprehensive cultivation of bioengineering majors in local colleges and universities. The results of this study will provide reference for the teaching reform of bioengineering major in local universities and cultivate innovative talents of higher quality.

Acknowledgements: This work was supported by Key Project in the 13th Five-Year Plan of Education Science in Heilongjiang Province (GJB1320232).

\section{REFERENCE}

1. Kang Q, Lu X, Xiong G. CDIO syllabus and engineering innovation talent training. Journal of higher education research. 2008; 31(4):15-18.

2. Crawley EF, Malmqvist J, Math Z, Stlund S, Brodeur DR. Rethinking Engineering Education: The CDIO Approach, Springer, New York. 2007.

3. Johan M. Ten Years of CDIO : Experiences from a Long-Term Education Development Process
[DB/OL]. [2012-06-01]. http: www.cdio.org/knowledge library/documents/ten years -cdio -experiences-long-term-educationdevelopment-process.

4. Malmqvisit J. Use of CDIO Standards in Swedish National Evaluation of Engineering Educational Programs [DB/OL]. [2012-06-01]. http:www. cdio. org/ knowledge - library/ documents / usecdio-standards-swedish-national-evaluationengineering-educational-p.

5. Ye M, Kong B, Zhang W. New Engineering: From Idea to Action. Higher Engineering Education Research, 2018; (1):24-31.

6. Wang B, Li B, Chen X. Teaching Reform and Practice of Undergraduate Courses based on "Double Tutorial SYSTEM CDIO". Laboratory Research and Exploration. 2016; (3):196-200.

7. Xie K, Sheng L, Tong LI. Exploration of Curriculum Reform of Embedded Systems in CDIO mode. Education \& Teaching Forum. 2018; (1):97-98.

8. Cao M, Liang Z. Role Transformation of engineering teachers based on CDIO Concept. Research on Higher Engineering Education. 2012; (1): 88-91. 